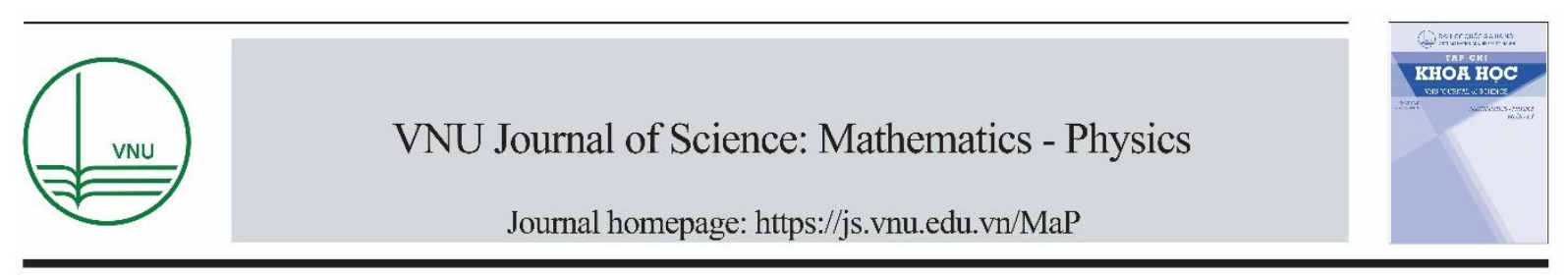

Original Article

\title{
Effect of K Substitutions on Structural and Superconducting Properties in $\mathrm{Bi}_{1.6} \mathrm{~Pb}_{0.4} \mathrm{Sr}_{2-\mathrm{x}} \mathrm{K}_{\mathrm{x}} \mathrm{Ca}_{2} \mathrm{Cu}_{3} \mathrm{O}_{10+\delta}$ Compounds
}

\author{
Tran Hai Duc ${ }^{1, *}$, Pham The $A n^{1}$, Do Thi Kim Anh ${ }^{1}$, \\ $\mathrm{Vu}$ Hoang Linh ${ }^{1,2}$, Pham Hoang $\mathrm{Ha}^{1,2}$, Nguyen Khac Man ${ }^{3}$ \\ ${ }^{1}$ Faculty of Physics, VNU University of Science, Hanoi, Vietnam \\ ${ }^{2}$ Faculty of Physics Teacher Education, VNU University of Education, Hanoi, Vietnam \\ ${ }^{3}$ International Training Institute of Material Science, HUST, Hanoi, Vietnam
}

Received 18 February 2019

Revised 3 April 2019; Accepted 17 April 2019

\begin{abstract}
Effect of $\mathrm{K}$ substitutions on structural and superconducting properties in $\mathrm{Bi}-\mathrm{Pb}-\mathrm{Sr}-\mathrm{Ca}-$ $\mathrm{Cu}-\mathrm{O}$ (BPSCCO) system has been investigated. Bulk $\mathrm{Bi}_{1.6} \mathrm{~Pb}_{0.4} \mathrm{Sr}_{2-\mathrm{x}} \mathrm{K}_{\mathrm{x}} \mathrm{Ca}_{2} \mathrm{Cu}_{3} \mathrm{O}_{10+\delta}$ (where $\mathrm{x}=$ $0.00 ; 0.04 ; 0.08$ and 0.1$)$ samples were fabricated by using the solid-state reaction method. Structural properties of the samples were examined by X-ray diffraction (XRD), scanning electron microscopy (SEM) and energy dispersive spectroscopy (EDS) measurement. All samples showed co-existence of $\mathrm{Bi}-2223$ and $\mathrm{Bi}-2212$ superconducting phases. Interestingly, a formation of the $\mathrm{Bi}$ 2223 was decelerated and that of the Bi-2212 was accelerated with increasing $\mathrm{K}$ content (x). Superconducting properties of the samples were characterized by using temperature dependences of resistance and field dependences of magnetization data. Both onset and offset transition temperatures were found to decrease, those were correlated to the decreases in residual resistance ratio (RRR). The $65 \mathrm{~K}$ magnetization curves of $\mathrm{K}$ - substituted samples were enlarged in comparison with that of the pure one. Enlargements of the magnetization curves were possibly attributed to the appearance of additional point-like defects generated by substitutions of $\mathrm{K}$ into $\mathrm{Sr}$ site.
\end{abstract}

Keywords: BPSCCO, substitutions, flux pinning, defects.

\section{Introduction}

From the end of the 1980s, a lot of studies has been focusing on high temperature superconductors (HTS) to deeply understand physical mechanisms and expand their power applications. The Bi-based

\footnotetext{
${ }^{*}$ Corresponding author.

Email address: dhtran@hus.edu.vn
}

https//doi.org/ 10.25073/2588-1124/vnumap.4324 
compounds either in bulk or wires have been attractive basing on their advantageous properties $[1,2]$. The Bi-Sr-Ca-Cu-O (BSCCO) system has three superconducting phases, those corresponds to an ideal formula of $\mathrm{Bi}_{2} \mathrm{Sr}_{2} \mathrm{Ca}_{n-1} \mathrm{Cu}_{\mathrm{n}} \mathrm{O}_{2 n+4+y}$, where $\mathrm{n}$ is the number of $\mathrm{CuO}_{2}$ planes $(\mathrm{n}=1,2$ and 3). Critical temperature $\left(T_{c}\right)$ of each phase is found to be $T_{c} \sim 20 \mathrm{~K}$ for $\mathrm{n}=1(\mathrm{Bi}-2201), \mathrm{T}_{\mathrm{c}} \sim 80 \mathrm{~K}$ for $\mathrm{n}=2(\mathrm{Bi}-$ 2212) and $\mathrm{T}_{\mathrm{c}} \sim 110 \mathrm{~K}$ for $\mathrm{n}=3(\mathrm{Bi}-2223)$ [3-6]. Among these phases, the Bi-2223 phase has been reported to be technically difficult to fabricate because the stability range for this phase is extremely narrow. Formation of the Bi-2223 phase was strongly depended on the experimental conditions consisting of sintering processes (temperature, duration, gas atmosphere), doping or substituting materials... One of the most well-known results for enhancing the formation of the $\mathrm{Bi}-2223$ phase was a partial substitution of $\mathrm{Pb}$ in to $\mathrm{Bi}$ site [7-9]. The sintering temperature for the $\mathrm{Bi}-2223$ phase was lowered from $\sim 880-890{ }^{\circ} \mathrm{C}$ to $\sim 850{ }^{\circ} \mathrm{C}$ as $\mathrm{Pb}$ was partially substituted [3], which helped to stable the $\mathrm{Bi}-2223$ phase. However, the enhanced formation of the Bi-2223 phase was relatively limited, which meant that the co-existence of the Bi-2223 and Bi-2212 still occurred. Disorder defects generated as a result of substitution effects were reported to effectively serve as pinning center to enhance flux pinning properties of HTS [10-14]. In this work, effect of potassium substitution on structural and superconducting properties of the BPSCCO, which had been hoped for improving, was investigated.

\section{Experiment}

Fabrication of $\mathrm{Bi}_{1.6} \mathrm{~Pb}_{0.4} \mathrm{Sr}_{2-\mathrm{x}} \mathrm{K}_{\mathrm{x}} \mathrm{Ca}_{2} \mathrm{Cu}_{3} \mathrm{O}_{10+\delta}$ bulk samples (where $\mathrm{x}=0.00 ; 0.04 ; 0.08$ and 0.1 ) were performed by using the conventional solid state reaction technique. An appropriate weight of high purity powders (99.9\%) of $\mathrm{Bi}_{2} \mathrm{O}_{3}, \mathrm{PbO}, \mathrm{SrCO}_{3}, \mathrm{~K}_{2} \mathrm{CO}_{3}, \mathrm{CaCO}_{3}$ and $\mathrm{CuO}$ was thoroughly mixed using agate pestle and mortar. The mixtures were pelleted and atmospherically calcinated at different temperatures of $670{ }^{\circ} \mathrm{C}, 750{ }^{\circ} \mathrm{C}, 800{ }^{\circ} \mathrm{C}, 820^{\circ} \mathrm{C}$ with each calcination period was kept to be 48 hours. The re-grinding and re-pelleting processes were applied before the next calcination step. Finally, all samples were sintered at $850{ }^{\circ} \mathrm{C}$ for 168 hours in the air and freely cooled to a room temperature.

To investigate the structural properties of the fabricated samples, the X-ray diffraction (XRD), scanning electron microscopy (SEM) and energy dispersive spectroscopy (EDS) measurements were used. The superconducting properties based on field dependences of magnetization were examined by using the Quantum Design MPMS XL-5 system.

\section{Results and discussions}

The crystallinity and the phase formations of the fabricated samples were examined by the XRD results as presented in Fig. 1.

The XRD patterns revealed that all samples were completely converted into Bi-2223 (denoted by "H") and Bi-2212 phases (denoted by "L") and no K-rich phase was observed. A little impurity peak, however, was found in all samples, which was identified to be $\mathrm{Ca}_{2} \mathrm{PbO}_{4}$ phase. Origin of formation of this phase was attributed to a chemical reaction of $\mathrm{Pb}$ and $\mathrm{Ca}$ during sample fabrication process $[15,16]$. To quantitively compare the formation of the two superconducting phases, the volume fractions for each were calculated by using the relation [15-17]:

$$
\% \mathrm{Bi}-2223=\frac{\sum \mathrm{I}_{2223}}{\sum \mathrm{I}_{2223}+\sum \mathrm{I}_{2212}} \times 100
$$




$$
\% \mathrm{Bi}-2212=\frac{\sum \mathrm{I}_{2212}}{\sum \mathrm{I}_{2223}+\sum \mathrm{I}_{2212}} \times 100
$$

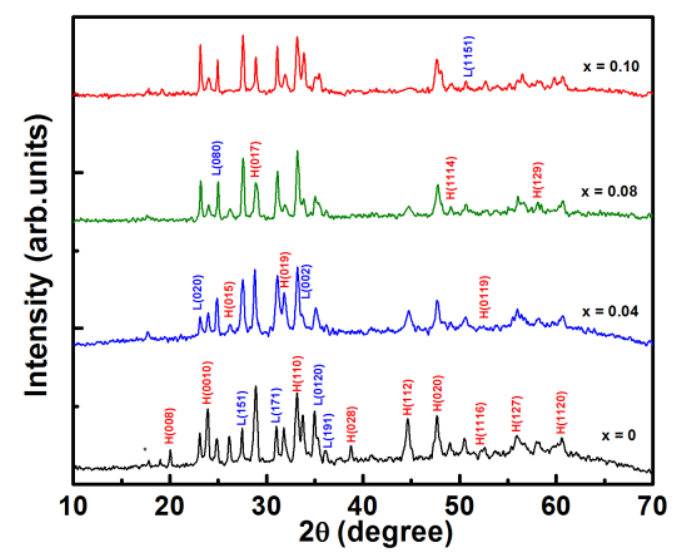

Figure 1. XRD diffraction patterns of the $\mathrm{Bi}_{1.6} \mathrm{~Pb}_{0.4} \mathrm{Sr}_{2-\mathrm{x}} \mathrm{K}_{\mathrm{x}} \mathrm{Ca}_{2} \mathrm{Cu}_{3} \mathrm{O}_{10+\delta}$ (where $\mathrm{x}=0.00 ; 0.04 ; 0.08$ and 0.1 ) bulk samples.

where $\mathrm{I}_{2223}$ and $\mathrm{I}_{2212}$ were intensity summations of the XRD peaks for the Bi-2223 and Bi-2212 phases, respectively. The calculated results were plotted as function of $\mathrm{K}$ content $(\mathrm{x})$ and given in Fig. 2.

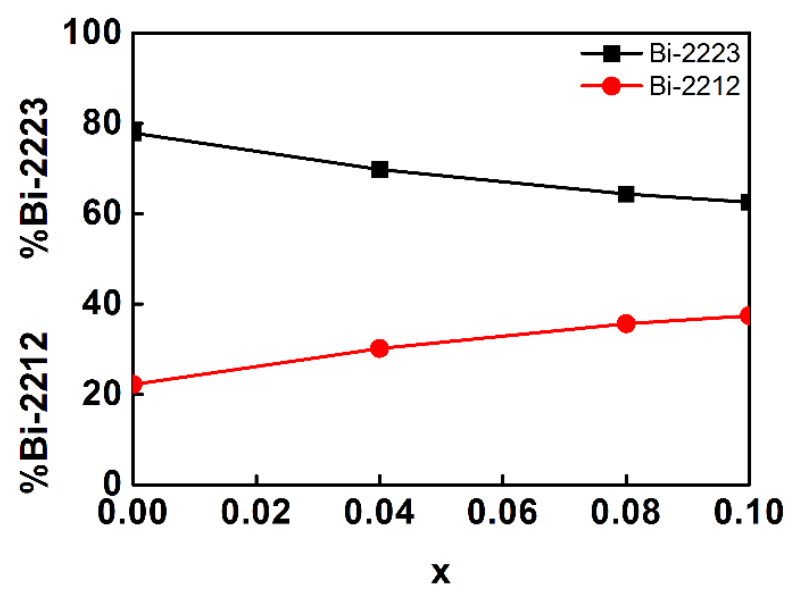

Figure 2. Variations of volume fraction of the Bi-2223 and Bi-2212 phases as function of K content (x)

It would be seen that volume fractions of the two superconducting phases were varied as increasing K content (x). \%Bi-2223 was found to continuously decrease from $77.92 \%$ to $62.56 \%$ while \% Bi-2212 was increased from $22.18 \%$ to $37.44 \%$. The results might indicate that the substitutions of $\mathrm{K}$ accelerated the formation of the Bi-2212 phase.

Superconductivity phases were observed on surface via SEM results as evidenced in Figure 3. 

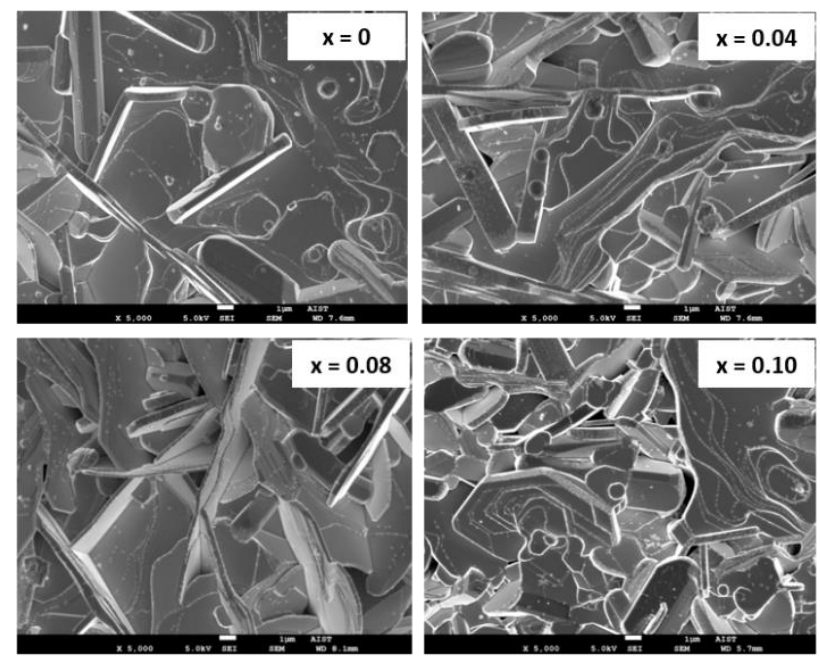

Figure 3. Typical surface morphology of the $\mathrm{Bi}_{1.6} \mathrm{~Pb}_{0.4} \mathrm{Sr}_{2-\mathrm{x}} \mathrm{K}_{\mathrm{x}} \mathrm{Ca}_{2} \mathrm{Cu}_{3} \mathrm{O}_{10+\delta}$ (where $\mathrm{x}=0.00 ; 0.04 ; 0.08$ and 0.1 ) bulk samples.

The grains reaffirmed co-existance of superconductivity phases in microstructure that Bi-2223 and Bi-2212 phases were observed in form of plate-like and needle-like, respectively [18]. Small spherelike grains, which have been known as the phases of $\mathrm{Ca}_{2} \mathrm{PbO}_{4}$ [9], were also found. Surface of pure sample was the most orderly, smooth and dense but continuously degraded as $\mathrm{x}$ increased to 0.1 . Besides, the average observed size of plate-like grains were also smaller. These obtained results were in agreement with the XRD analyses.

Elemental analysis of $\mathrm{x}=0.1$ sample was performed via EDS result as demonstrated in Figure. 4.

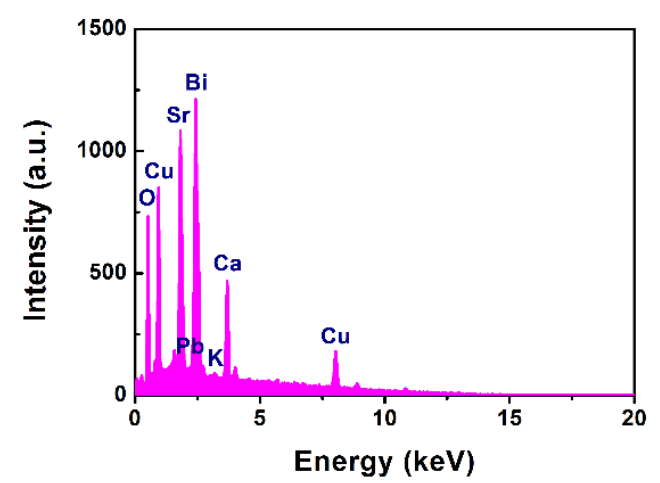

Figure 4. EDS elemental analysis of the $\mathrm{Bi}_{1.6} \mathrm{~Pb}_{0.4} \mathrm{Sr}_{1.9} \mathrm{~K}_{0.1} \mathrm{Ca}_{2} \mathrm{Cu}_{3} \mathrm{O}_{10+\delta}$ sample.

Elements of the sample were observed completely by high intensity peak from energetic range of 0 to $10 \mathrm{keV}$ as found results [15]. Furthermore, the peak of $\mathrm{K}$ was found in about $3.313 \mathrm{keV}$, which is known as the potassic energy for EDS [15]. This result affirmed $\mathrm{K}$ had been doped successfully into the high superconductivity compound. Moreover, the small intensity of potassium showed that doping concentration is low. 
Superconducting transitions in pure and K-substituted samples were examined by using the four probe measurement. The normalized resistance versus temperature data of the samples were provided in Figure. 5.



Figure 5. Temperature dependence of normalized resistance of the $\mathrm{Bi}_{1.6} \mathrm{~Pb}_{0.4} \mathrm{Sr}_{2-\mathrm{x}} \mathrm{K}_{\mathrm{x}} \mathrm{Ca}_{2} \mathrm{Cu}_{3} \mathrm{O}_{10+\delta}$ (where $\mathrm{x}=0.00 ; 0.04 ; 0.08$ and 0.1 ) bulk samples.

All samples showed the metallic like behavior at high temperature region then followed by the superconducting transition. A transition area was defined to stay between onset and offset critical temperatures $\left(T_{c, \text { onset }}\right.$ and $\left.T_{c, \text { offset }}\right)$ [19-20]. Both values of $T_{c, \text { onset }}$ and $T_{c, \text { offset }}$ were found to continuously decrease as increasing $\mathrm{K}$ content $(\mathrm{x})$ as revealed in Figure. 6.

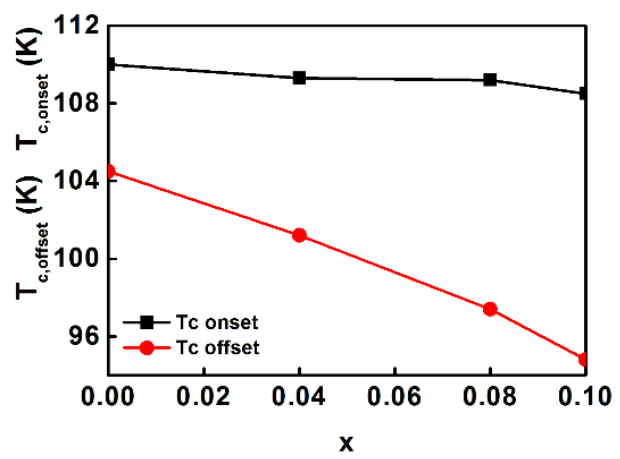

Figure 6. Degradations of $\mathrm{T}_{\mathrm{c}, \text { onset }}$ and $\mathrm{T}_{\mathrm{c}, \text { offset }}$ of the samples as a function of $\mathrm{K}$ content $(\mathrm{x})$.

In literatures, the both $T_{c}$ values of the samples were depended on the volume fraction of superconducting phases. The decrease in the $\% \mathrm{Bi}-2223$ as found in XRD results was likely to be a reason to those of both $T_{c}$ values. The quality of the samples was possibly examined by using the residual resistance ratio (RRR) obtained as $\mathrm{R}(300 \mathrm{~K}) / \mathrm{R}(120 \mathrm{~K})$ [19]. The larger the RRR is, the higher the sample quality is. Particularly, the observed increases in $\mathrm{R}(120 \mathrm{~K})$ in the K-substituted samples were probably attributed to the increased impurity scattering in the BPSCCO lattice, leading to slight degradations in superconductivity of the samples. Dependences of $T_{c, \text { onset }}$ and $T_{c, \text { offset }}$ on RRR values were given in Figure 7. 


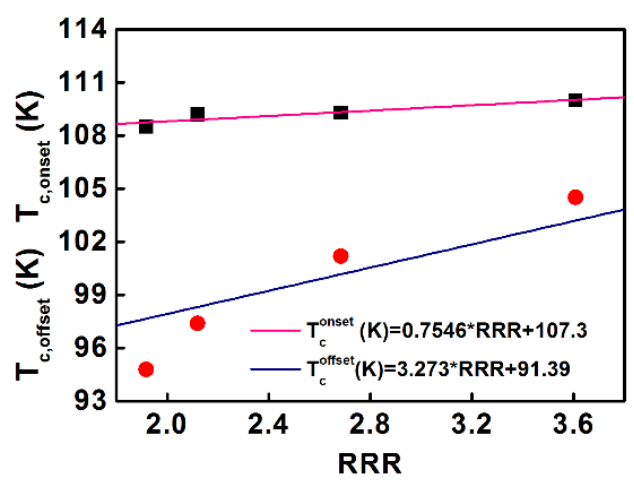

Figure 7. Dependences of $T_{c, \text { onset }}$ and $T_{c, \text { offset }}$ on the residual resistance ratio (RRR) of the samples. High values of the RRR indicated the high sample quality.

It was visible that the data were well fitted by simple linear equations. The extrapolated critical temperatures were obtained to be $107.3 \mathrm{~K}$ for $\mathrm{T}_{\mathrm{c}, \text { onset }}$ and $91.39 \mathrm{~K}$ for $\mathrm{T}_{\mathrm{c}, \text { offset. }}$. Another feature might be deduced from the decreases in both $\mathrm{T}_{\mathrm{c}, \text { onset }}$ and $\mathrm{T}_{\mathrm{c}, \text { offset }}$. As widely reported, $\mathrm{T}_{\mathrm{c} \text {,onset }}$ was consistent with the superconducting transition of isolated grains, and $\mathrm{T}_{\mathrm{c}, \text { offset }}$ was in association with the superconducting transition of inter-granular components [17-21]. In our work, $\mathrm{T}_{\mathrm{c}, \text { offset }}$ Was compared to decrease faster than that of $\mathrm{T}_{\mathrm{c} \text {,onset }}$, which might reveal the fact that the inter-granular components were more affected. As a result, more disorder defects were believed to be generated by the Ksubstitutions.

BSCCO has been classified to be type II superconductors whose a mixed state consisting of superconducting and non-superconducting phases. Applied fields (below $\mathrm{H}_{\mathrm{c} 2}$ ) were able to penetrate into BSCCO in forms of vortices (quantized fields). According to the Ampere law, the critical current density $\left(\mathrm{J}_{\mathrm{c}}\right)$ would be enhanced [11-15]. Unfortunately, the vortices would be acted by the Lorentz force as applying current through sample. To pin the vortices, hence, has become a technological issue. It has been widely reported that these vortices might be pinned via nanosized crystal defects called pinning centers. The generated disorders discussed above were potential candidates for such a wonderful role. To examine the pinning effect, the magnetization curves of the samples at $65 \mathrm{~K}$ were measured and given in Figure. 8.

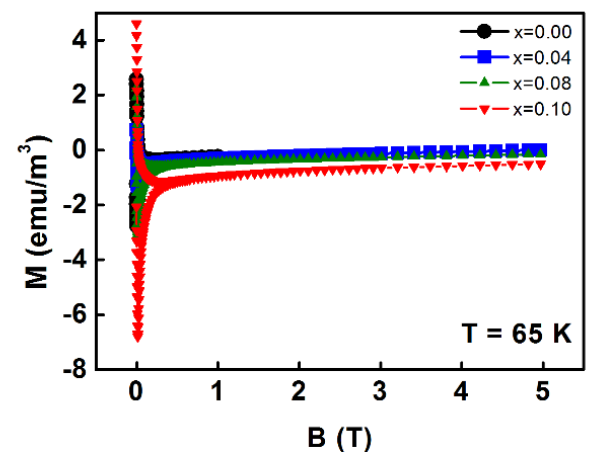

Figure 8: Field dependence of normalized magnetization curves of the the $\mathrm{Bi}_{1.6} \mathrm{~Pb}_{0.4} \mathrm{Sr}_{2-\mathrm{x}} \mathrm{K}_{\mathrm{x}} \mathrm{Ca}_{2} \mathrm{Cu}_{3} \mathrm{O}_{10+\delta}$ (where $\mathrm{x}$ $=0.00 ; 0.04 ; 0.08$ and 0.1$)$ bulk samples measured at $65 \mathrm{~K}$. Improvements of flux pinning properties were evidenced by the enlargements of curve areas. 
Generally, all samples showed the typical magnetization curves for anisotropic type II superconductors. The diamagnetic signals were obtained as increasing the applied fields. In comparison, areas of the magnetization curves for the K-substituted samples were found to be larger than that for the pure ones. The findings might indicate that the trapped fields via pinning centers in the K-substituted samples were obviously enhanced. Moreover, the values of irreversibility field defined as the fields at which $\Delta \mathrm{M}$ became zero the $\mathrm{K}$-substituted samples were also increased. The combined results might be used as strong evidences for improvements of flux pinning properties in BPSCCO samples by the K substitutions [15]. The improvements, however, occurred differently with $\mathrm{K}$ substitution levels. Origin of those behaviors was attributed to pinning centers in forms of additional point-like defects. As $\mathrm{K}$ content (x) increased, the density of that pinning centers was also changed, leading to the variously observed improvements.

\section{Conclusions}

Structural and superconducting properties in $\mathrm{Bi}_{1.6} \mathrm{~Pb}_{0.4} \mathrm{Sr}_{2-\mathrm{x}} \mathrm{K}_{\mathrm{x}} \mathrm{Ca}_{2} \mathrm{Cu}_{3} \mathrm{O}_{10+\delta}$ (where $\mathrm{x}=0 ; 0.04 ; 0.08$ and 0.1) samples were studied. Bulk samples were fabricated by using the conventional solid state reaction technique. From the XRD results, it was evident that two superconducting phases of Bi-2223 and $\mathrm{Bi}-2212$ were formed. The $\mathrm{K}$ substitutions accelerated the formation of the Bi-2212 and decelerated that of the Bi-2223. Consequently, both transition temperatures $\mathrm{T}_{\mathrm{c} \text {,onset }}$ and $\mathrm{T}_{\mathrm{c} \text {,offset }}$ were decreased. The residual resistance ratio (RRR) was also found to decrease as increasing $\mathrm{K}$ content, which was likely to link to the enhanced impurity and disorders. Positive effect of $\mathrm{K}$ substitutions were obtained in flux pinning properties. Magnetization curves of the $\mathrm{K}$ substituted samples were enlarged, which revealed the generations of point-like defects.

\section{Acknowledgement}

This research is funded by Vietnam National Foundation for Science and Technology Development (NAFOSTED) under grant number 103.02-2016.11.

\section{References}

[1] H. Maeda, Y. Tanaka, M. Fukutomi, T. Asano, Jpn. J. Appl. Phys. 27 (1988) L209 - L210.

[2] M.H. Mohammed, R. Awad, A.I. Abou - Aly, I.H. Ibrahim, M.S. Hassan, Materials Sciences and Applications 3 (2012) $224-233$.

[3] S.E. M. Ghahfarokhi, M. Z. Shoushtari, Physica B. 405 (22) (2010) 4643 - 4649.

[4] C.N.R. Rao, L. Ganapathi, R. Vijayaraghavan, G.R. Rao, K. Murthy, R.A. Mohan Ram, Physica C. 156(5) (1988) $827-833$.

[5] S.A. Sunshine, T. Siegrist, L.F. Schneemeyer, D.W. Murphy, R.J. Cava, B. Batlogg, R.B. van Dover, R.M. Fleming, S.H. Glarum, S. Nakahara, R. Farrow, J.J. Krajewski, S.M. Zahurak, J.V. Waszczak, J.H. Marshall, P. Marsh, L.W. Rupp, Jr., W.F. Peck, Structure and physical properties of single crystals of the 84-K superconductor $\mathrm{Bi}_{2.2} \mathrm{Sr}_{2} \mathrm{Ca}_{0.8} \mathrm{Cu}_{2} \mathrm{O}_{8+\delta}$, Phys. Rev. B. 38 (1988) $893-896$.

[6] M. Takano, J. Takada, K. Oda, H. Kitaguchi, Y. Miura, Y. Ikeda, Y. Tomii, H. Mazaki, High-T ${ }_{c}$ Phase Promoted and Stabilized in the Bi, Pb-Sr-Ca-Cu-O System, Jpn. J. Appl. Phys. 27 (1988) L1041 - L1043.

[7] C. Michel, M. Hervieu, M. M. Borel, A. Grandin, F. Deslandes, J. Provost, B. Raveau, Superconductivity in the $\mathrm{Bi}$ - Sr - Cu - O system, Zeitschrift für Physik B Condensed Matter 68 (4) (1987) 421 - 423. 
[8] J. Akimitsu, A. Yamazaki, H. Sawa, H. Fujiki, Superconductivity in the Bi - Sr - Cu - O system, Jpn. J. Appl. Phys. 26 (12) (1987) L2080 - L2008.

[9] B. Ozkurt, Improvement of the critical current density in Bi-2223 ceramics by sodium-silver co-doping, J. Mater. Sci.: Mater. Electron. 25 (2014) 3295 - 3300.

[10] O. Bilgili, Y. Selamet, K. Kocabas, Effects of Li Substitution in Bi-2223 Superconductors, J. Supercond. Nov. Magn. 21 (2008) 439 - 449.

[11] M. Ebru Kır, B. Özkurt and M. Ersin Aytekin, The effect of K-na co-doping on the formation and particle size of Bi-2212 phase, Physica B 490 (2016) 79 - 85.

[12] H.Y. Wu, K.Q. Ruan, J. Yin, S.L. Huang, Z.M. Lv, M. Li, L.Z. Cao, Effect of K and Nd substitutions on superconductivity of Bi2223 superconductors, Supercond. Sci. Technol. 20 (2007) 1189 - 1192.

[13] A.K. Pradhan, S.B. Roy, P. Chaddah, C. Chen, B.M. Wanklyn, Magnetic properties of singlecrystal $\mathrm{Bi}_{2} \mathrm{Sr}_{2} \mathrm{CaCu}_{2} \mathrm{O}_{8+\mathrm{y}}$ : Experimental evidence for a dimensional crossover, Phys. Rev. B 49 (1994) $12984-$ 12989.

[14] A. Biju, K. Vinod, P.M. Sarun, U. Syamaprasad, Highly enhanced flux pinning in $\mathrm{Pb}$ and rare earth codoped Bi2212, Appl. Phys. Lett. 90 (2007) 072505.

[15] S. Vinu, P.M. Sarun, R. Shabna, A. Biju, U. Syamaprasad, Enhancement of critical current density and flux pinning properties of Gd-doped (Bi,Pb)-2212 superconductor, J. Appl. Phys. 104 (2008) 043905.

[16] Y.L. Chen, R. Stevens, 2223 Phase Formation in $\mathrm{Bi}(\mathrm{Pb})-\mathrm{Sr}-\mathrm{C}-\mathrm{a}-\mathrm{Cu}-\mathrm{O}$ : II, The Role of TemperatureReaction Mechanism, J. Am. Ceram. Soc. 75(5) (1992) 1150 - 1159.

[17] H. Sozeri, N. Ghazanfari, H. Ozkan, A. Kilic, Enhancement in the high-Tc phase of BSCCO superconductors by $\mathrm{Nb}$ addition, Supercond. Sci. Technol. 20 (2007) $522-528$.

[18] S. Hirano, Y. Wakasa, A. Saka, S. Yoshizawa, Y. Oya-Seimiya, Y. Hishinuma, A. Nishimura, A. Matsumoto, H. Kumakura, Preparation of Bi-2223 bulk composed with silver-alloy wire, Physica C 458 (2003) 392 - 396.

[19] G. Yildirim, Determination of optimum diffusion annealing temperature for Au surface-layered Bi-2212 ceramics and dependence of transition temperatures on disorders, J. Alloy. Compd. 699 (2017) $247-255$.

[20] B. Ozkurt, Structural and magnetic properties of $\mathrm{Li}$ and $\mathrm{Na}$ added $\mathrm{Bi}_{1.8} \mathrm{Sr}_{2.1}(\mathrm{Li}, \mathrm{Na})_{\mathrm{x}} \mathrm{Ca}_{1.1} \mathrm{Cu}_{2.2} \mathrm{O}_{\mathrm{y}}(\mathrm{Bi}-2212)$ ceramics ( $x=0,0.05,0.1$ and 0.2), J. Mater Sci, Mater Electron 28 (2017) 8857 - 8863. 